\title{
Influence of subclinical hypothyroidism on metabolic parameters in obese children and adolescents
}

\author{
Ozlem Kara, MD \\ Department of Pediatric Endocrinology, Bursa Yuksek Intisas Training and Research Hospital, Bursa, Turkey
}

Background: Subclinical hypothyroidism $(\mathrm{SH})$ is a common condition in obese children. However, its effect on glucose and lipid metabolism in obese children remains controversial.

Purpose: The present study aimed to investigate the association between $\mathrm{SH}$ and metabolic parameters.

Methods: A total of 215 obese children and adolescents aged 6-18 years were included in this retrospective cross-sectional study. The patients' anthropometric measurements such as thyrotropin (TSH), free thyroxine (fT4), fasting plasma glucose, and insulin levels, as well as homeostasis model assessment for insulin resistance (HOMA-IR) index, and lipid profiles were evaluated. The patients were allocated to the $\mathrm{SH}$ group (fT4 normal, TSH 5-10 mIU/L) ( $\mathrm{n}=77)$ or the control group (fT4 normal, TSH<5 mIU/L) $(\mathrm{n}=138)$. The glucose and lipid metabolisms of the 2 groups were compared.

Results: SH was identified in 77 of 215 patients (36\%). Mean body mass index was similar in both groups. The mean serum insulin, HOMA-IR, and triglyceride (TG) levels were higher and the mean high-density lipoprotein cholesterol level was lower in the SH group than in the control group $(P=0.007$, $P=0.004, P=0.01$, and $P=0.02$, respectively). A positive correlation was observed between TSH level and insulin level, HOMA-IR, and TG level.

Conclusion: $\mathrm{SH}$ was identified in some of the obese children and adolescents. A clear association was observed between $\mathrm{SH}$, insulin resistance, and dyslipidemia in obese children.

Key words: Child, Dyslipidemia, Insulin resistance, Obesity, Subclinical hypothyroidism

\section{Key message}

Question: Does subclinical hypothyroidism in obese children and adolescents affect metabolic parameters?

Finding: Insulin, HOMA-IR, and TG levels were higher and the HDL-C level was lower in patients with $\mathrm{SH}$.

Meaning: A clear association is observed between $\mathrm{SH}$, and insulin resistance and dyslipidemia in obese children. It can be said that the TSH may be evaluated as a metabolic risk factor in obese patients.

\section{Introduction}

The prevalence of childhood obesity has increased by $5 \%$ each decade during the past 50 years and about $25 \%$ of all children are overweight or obese. ${ }^{1)}$ Obesity may result in complications like dyslipidemia, hypertension, and impaired glucose metabolism. ${ }^{2)}$ Thyroid hormones regulate the basal metabolism through playing a role in lipid and glucose metabolism. ${ }^{3)}$ Thyroid dysfunction leads to changes in body weight and composition. ${ }^{4)}$ As a result, the association between obesity and thyroid dysfunction has drawn attention. Subclinical hypothyroidism $(\mathrm{SH})$ is defined as a thyrotropin (TSH) level of above the reference values despite normal serum free thyroxine (fT4) levels, and $\mathrm{SH}$ is more frequent in obese children and adolescents compared to subjects with normal weight. ${ }^{5-7)}$ The underlying mechanism of thyroid hormone alterations in the obese is not clear. ${ }^{8)}$ However, various mechanisms including iodine deficiency, autoimmune thyroid disease, TSH receptor gene mutation, thyroid hormone resistance, increased leptin levels, leptin-mediated production of pro-TSH-releasing hormone, impaired feedback due to a lowered number of T3 receptors in the hypothalamus and decrease in peripheral deiodinase activity have been proposed. ${ }^{6,8}$ Besides, a positive correlation was found between the body mass index (BMI) and the TSH level in various studies conducted with the euthyroid obese (children who are above 95th BMI percentile for age and sex having normal thyroid function). ${ }^{9,10)}$ Furthermore, the TSH levels are observed to increase with increasing weight. ${ }^{11)}$ All these changes in the obese are considered to be an adaptation for increasing the resting energy expenditure. ${ }^{12)}$

Assessment of thyroid functions is important in the obese as hypothyroidism is a cause of obesity. However, $\mathrm{SH}$ seems to be a result of obesity rather than the cause as TSH levels decrease with losing weight despite the absence of a consensus on this issue. ${ }^{8)}$ Treatment of $\mathrm{SH}$ in the obese is still of debate. Obesity-related glucose and lipid metabolism changes may be observed. Studies in children and adolescents are limited despite the presence of many adult studies investigating the relationship between the TSH level and metabolic parameters.

The present study was conducted with the aim of investigating

\footnotetext{
Corresponding author: Ozlem Kara, MD. Department of Pediatric Endocrinology, Bursa Yuksek Ihtisas Training and Research Hospital, Mimar Sinan Mah. Emniyet Cad. Polis Okulu Kar Isı Yıldırım/Bursa, 16310, Turkey 


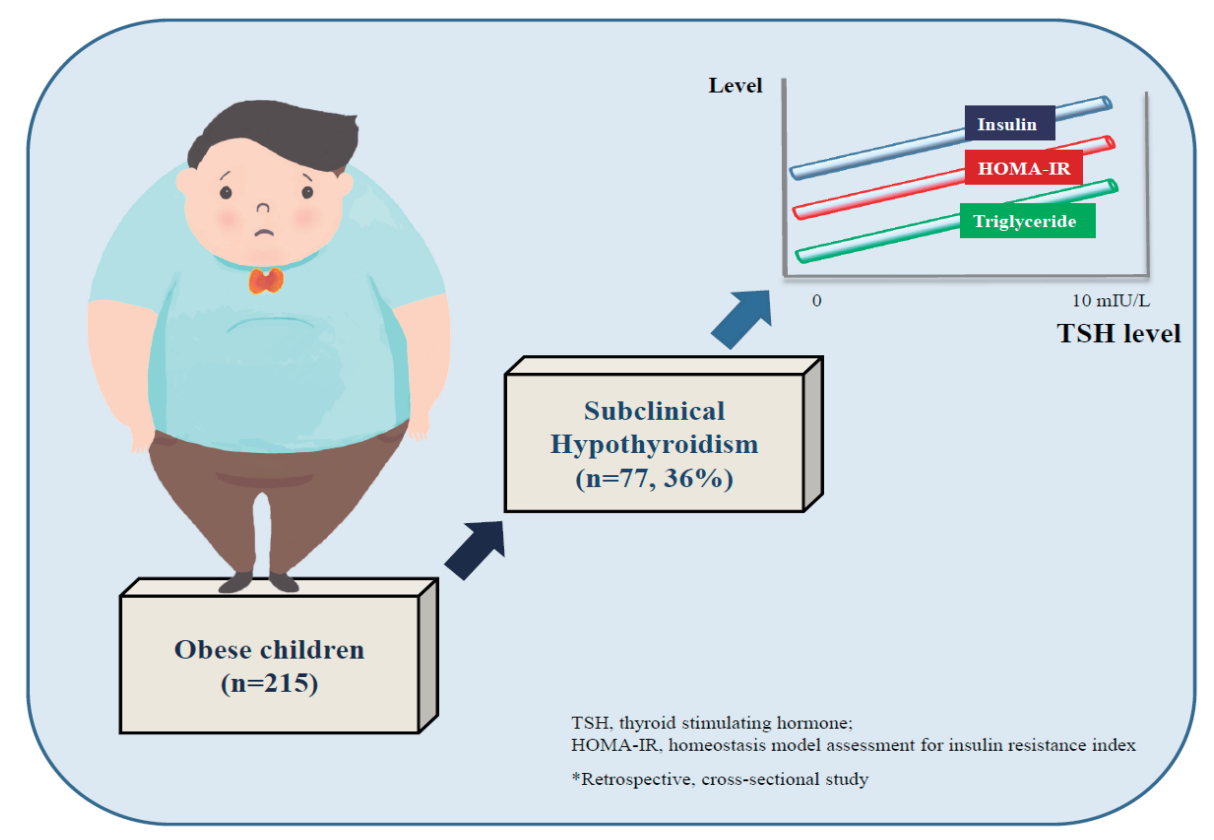

Graphical abstract. The effect of subclinical hypothyroidism on metabolic parameters in obese children

the changes in glucose and lipid metabolism in obese children and adolescents with $\mathrm{SH}$, and comparing these changes with those of euthyroid obese children and adolescents.

\section{Methods}

\section{Study population}

Patients aged between 6-18 years, who had been admitted to the Pediatric Endocrinology Outpatient Clinic of Bursa Yuksek Ihtisas Hospital with the complaint of being overweight between 1 October 2018 and 30 March 2019 and whose BMI $>95$ th percentile for age and sex were included in the study. The study protocol was approved by the ethics committee of the Bursa Yuksek Ihtisas Training and Research Hospital (2011KAEK-25 2019/03-05) in accordance with the principles of the Helsinki Declaration. Data regarding age, sex, puberty, anthropometric measurements, and laboratory and radiology results were retrospectively collected from patient files. Patients who had missing data, whose thyroid auto-antibodies (antithyroid peroxidase, antithyroglobulin) were positive, whose TSH was $>10 \mathrm{mIU} / \mathrm{L}$ and fT4 was low according to age, whose thyroid ultrasonography results were not normal, who had chronic diseases or medication use and secondary obesity, were excluded from the study. A total of 215 obese patients, the complete data of whom could be reached, whose thyroid auto-antibodies were negative and thyroid ultrasonography results were normal, were included in the study. Weight $(\mathrm{kg})$, height $(\mathrm{cm})$, BMI $(\mathrm{kg} /$ $\mathrm{m}^{2}$ ), BMI standard deviation score (SDS), puberty status and waist circumference of the patients were recorded. Laboratory analyses included TSH, fT4, fasting plasma glucose, homeostasis model assessment for insulin resistance (HOMA-IR), triglyceride (TG), total cholesterol (TC), high-density lipoprotein cholesterol
(HDL-C), low-density lipoprotein cholesterol (LDL-C), aspartate aminotransferase, and alanine aminotransferase values. The patients were allocated to 2 groups according to thyroid function test results. Subjects whose fT4 level was normal and TSH level was $5-10 \mathrm{mIU} / \mathrm{L}$ were enrolled in the $\mathrm{SH}$ group. The subjects whose fT4 level was normal and TSH level was $<5 \mathrm{mIU} / \mathrm{L}$ were enrolled in the control group. Both groups were compared with regard to fasting plasma glucose, insulin, HOMA-IR, and lipid profile.

\section{Anthropometric examination}

The weight measurements of all patients were carried out using the Tess BM 300 device (Comak tarti, Istanbul, Turkey), at $0.1-\mathrm{kg}$ sensitivity and on an empty stomach, without shoes and with daily clothes. The height measurements were made with a stadiometer with an error of $1 \mathrm{~mm}$ with bare feet, standing upright, and the shoulder and gluteal area touching the wall. All measurements were made between 9:00 AM and 16:00 PM by the same person. BMI was calculated by using the formula: body weight/ height ${ }^{2}\left(\mathrm{~kg} / \mathrm{m}^{2}\right)$.

\section{Laboratory measurements}

The serum fasting blood glucose, TC, TG, HDL-C, LDL-C, and insulin levels were tested after 12 hours of fasting. The serum blood glucose and lipids were tested using the standard methods with the 'Cobas 8000' (Roche Diagnostics Turkey, Istanbul, Turkey) equipment. Insulin was measured using the standard method with the 'Cobas 8000' equipment. Insulin resistance was calculated using the HOMA-IR formula (fasting blood glucose $[\mathrm{mg} / \mathrm{dL}] \times$ fasting insulin $[\mu \mathrm{IU} / \mathrm{mL}] / 405)$. The serum TSH (reference range, $0.5-5 \mathrm{mIU} / \mathrm{L}$ ) and fT4 (reference range, 0.8$1.9 \mathrm{ng} / \mathrm{mL}$ ) were analyzed using chemiluminescence immune assays method. 


\section{Statistical analysis}

Statistical analyses were performed using the IBM SPSS Statistics ver. 21.0 (IBM Co., Armonk, NY, USA). The categorical variables were analyzed using the chi-square test. The Student $t$ test and the Mann-Whitney $U$ test were used for comparison of groups according to the parametric values. For correlation analyses, the Pearson test was used for the parametric variables and the Spearman test was used for the nonparametric variables. A $P$ value $<0.05$ was accepted as statistically significant.

\section{Results}

\section{Clinical characteristics of the subjects}

A total of 215 patients were included in the study. There were 141 females (66\%) and 74 males (34\%). Mean ages of subjects were $12.33 \pm 2.86$ years. The anthropometric and laboratory data of the patients have been summarized in Table 1.

\section{Comparison of anthropometric and laboratory parameters between $\mathrm{SH}$ and control groups}

$\mathrm{SH}$ was determined in a total of 77 patients (36\%). There were 138 patients $(64 \%)$ in the control group whose thyroid function test results were normal. No difference was found between the groups with regard to sex distribution $(P=0.65)$. The puberty status was similar in both groups $(P=0.92)$. While the mean BMI SDS was $2.47 \pm 0.67$ in the SH group, it was $2.55 \pm 0.57$ in the control group. Both groups were similar with regard to BMI SDS $(P=0.16)$. When groups were compared with regard to glucose metabolism, the fasting insulin and the HOMA-IR were

Table 1. Subjects' clinical characteristics

\begin{tabular}{lc}
\hline Characteristic & Value \\
\hline Total No. of patients & $215(100)$ \\
Sex & \\
Female & $141(66)$ \\
Male & $74(34)$ \\
Age $(\mathrm{yr})$ & $12.33 \pm 2.86$ \\
Body weight $(\mathrm{kg})$ & $70.19 \pm 19.77$ \\
Height $(\mathrm{cm})$ & $152.84 \pm 12.26$ \\
Body mass index $\left(\mathrm{kg} / \mathrm{m}^{2}\right)$ & $29.57 \pm 5.49$ \\
Body mass index SDS & $2.52 \pm 0.61$ \\
Waist circumference $(\mathrm{cm})$ & $98.75 \pm 12.72$ \\
Fasting glucose $(\mathrm{mg} / \mathrm{dL})$ & $89.24 \pm 7.68$ \\
Fasting insulin $(\mu \mathrm{lU} / \mathrm{mL})$ & $18.43 \pm 9.53$ \\
HOMA-IR & $4.10 \pm 2.31$ \\
Total cholesterol $(\mathrm{mg} / \mathrm{dL})$ & $164.51 \pm 34.70$ \\
HDL-cholesterol $(\mathrm{mg} / \mathrm{dL})$ & $46.05 \pm 9.71$ \\
LDL-cholesterol $(\mathrm{mg} / \mathrm{dL})$ & $96.46 \pm 27.57$ \\
Triglycerides $(\mathrm{mg} / \mathrm{dL})$ & $109.97 \pm 47.09$ \\
AST (U/L) & $21.53 \pm 7.45$ \\
ALT (U/L) & $21.56 \pm 13.78$ \\
\hline
\end{tabular}

Values are presented as number (\%) or mean \pm standard deviation.

SDS, standard deviation score; HOMA-IR, homeostasis model assessment for insulin resistance; HDL, high-density lipoprotein; LDL, low-density lipoprotein; AST, aspartate aminotransferase; ALT, alanine aminotransferase. found to be higher in the SH group $(P=0.007$ and $P=0.004$, respectively). When the groups were compared with regard to lipid metabolism, while the HDL-C level was found to be lower, the TG level was seen to be higher in the SH group than control group ( $P=0.02$ and $P=0.01$, respectively). The anthropometric and laboratory measurements of both groups have been sum. marized in Table 2.

\section{Correlations between TSH and metabolic parameters}

There was a positive correlation between TSH level and some metabolic parameters such as insulin $(r=0.20, P=0.003)$, HOMA-IR $(r=0.20, P=0.003)$, and TG $(r=0.21, P=0.001)$. There was no correlation between TSH level and BMI and waist circumference. The correlation between TSH and metabolic parameters has been shown in Figs. 1-3.

\section{Discussion}

In the present study, the relationship between TSH level and

Table 2. Subjects' anthropometric characteristics and laboratory parameters by study group

\begin{tabular}{|c|c|c|c|}
\hline Variable & $\begin{array}{c}\text { Obese with } \\
\text { subclinical } \\
\text { hypothyroidism }\end{array}$ & $\begin{array}{l}\text { Obese with } \\
\text { normal thyroid } \\
\text { function }\end{array}$ & $P$ value \\
\hline No. of patients & $77(36)$ & $138(64)$ & \\
\hline Sex & & & $0.65^{\text {a) }}$ \\
\hline Female & $49(64)$ & $92(67)$ & \\
\hline Male & $28(36)$ & $46(33)$ & \\
\hline Pubertal status & & & $0.92^{\mathrm{a})}$ \\
\hline Prepubertal & $18(23)$ & $33(24)$ & \\
\hline Pubertal & $59(77)$ & $105(76)$ & \\
\hline Age (yr) & $12.32 \pm 2.81$ & $12.33 \pm 2.83$ & $0.98^{\mathrm{b})}$ \\
\hline Body weight $(\mathrm{kg})$ & $68.14 \pm 19.45$ & $71.34 \pm 19.91$ & $0.25^{c)}$ \\
\hline Height (cm) & $151.41 \pm 12.16$ & $153.65 \pm 12.29$ & $0.20^{c)}$ \\
\hline $\mathrm{BMI}\left(\mathrm{kg} / \mathrm{m}^{2}\right)$ & $29.10 \pm 5.03$ & $29.84 \pm 5.73$ & $0.27^{\mathrm{c})}$ \\
\hline BMI SDS & $2.47 \pm 0.67$ & $2.55 \pm 0.57$ & $0.16^{\mathrm{c})}$ \\
\hline Waist circumference $(\mathrm{cm})$ & $98.14 \pm 13.75$ & $99.09 \pm 12.15$ & $0.60^{\mathrm{b})}$ \\
\hline $\mathrm{TSH}(\mathrm{mlU} / \mathrm{L})$ & $6.29 \pm 0.98$ & $2.51 \pm 0.95$ & $<0.001^{c)}$ \\
\hline fT4 (ng/dL) & $1.18 \pm 0.18$ & $1.19 \pm 0.17$ & $0.61^{c)}$ \\
\hline Fasting glucose (mg/dL) & $90.60 \pm 8.47$ & $88.48 \pm 7.13$ & $0.06^{\mathrm{c})}$ \\
\hline Fasting insulin ( $\mu \mathrm{lU} / \mathrm{mL})$ & $21.52 \pm 12.48$ & $16.70 \pm 6.87$ & $0.007^{c)}$ \\
\hline HOMA-IR & $4.87 \pm 3.10$ & $3.66 \pm 1.56$ & $0.004^{\mathrm{c})}$ \\
\hline Total cholesterol (mg/dL) & $162.48 \pm 27.80$ & $165.64 \pm 33.73$ & $0.48^{\mathrm{b})}$ \\
\hline HDL- cholesterol (mg/dL) & $44.13 \pm 9.58$ & $47.12 \pm 9.65$ & $0.02^{c)}$ \\
\hline LDL- cholesterol (mg/dL) & $94.78 \pm 26.50$ & $97.39 \pm 28.20$ & $0.50^{\mathrm{b})}$ \\
\hline Triglyceride (mg/dL) & $121.58 \pm 54.05$ & $103.49 \pm 41.54$ & $0.01^{c)}$ \\
\hline AST (U/L) & $20.45 \pm 6.78$ & $22.14 \pm 7.77$ & $0.06^{c)}$ \\
\hline $\operatorname{ALT}(\mathrm{U} / \mathrm{L})$ & $22.02 \pm 14.48$ & $21.30 \pm 13.42$ & $0.59^{c)}$ \\
\hline
\end{tabular}

Values are presented as number (\%) or mean \pm standard deviation. BMI, body mass index; SDS, standard deviation score; TSH, thyrotropin; fT4, free thyroxine; HOMA-IR, homeostasis model assessment for insulin resistance; HDL, high-density lipoprotein; LDL, low-density lipoprotein; AST, aspartate aminotransferase; ALT, alanine aminotransferase.

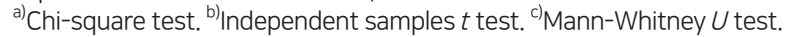
Boldface indicates a statistically significant difference with $P<0.05$. 


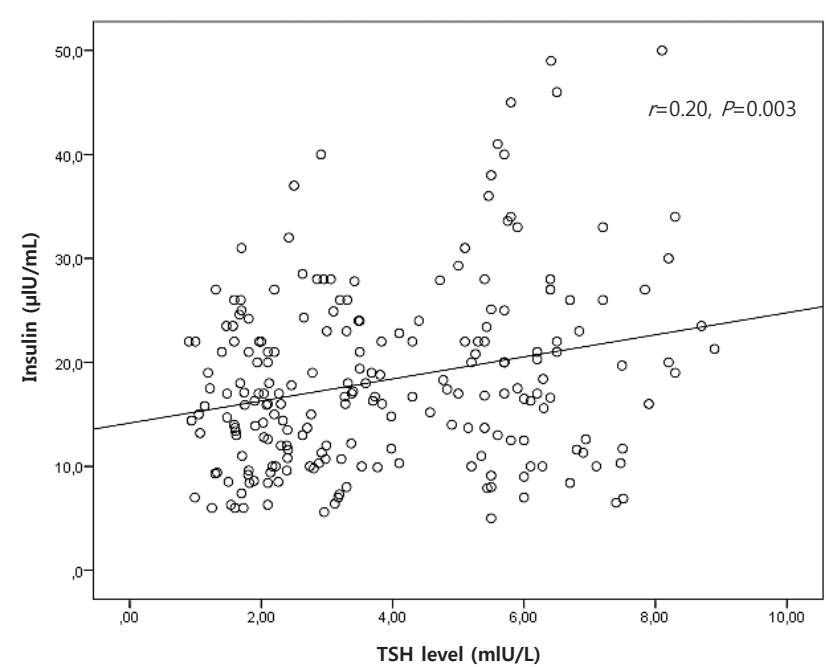

Fig. 1. Correlation between thyrotropin (TSH) level and insulin level in obese patients.

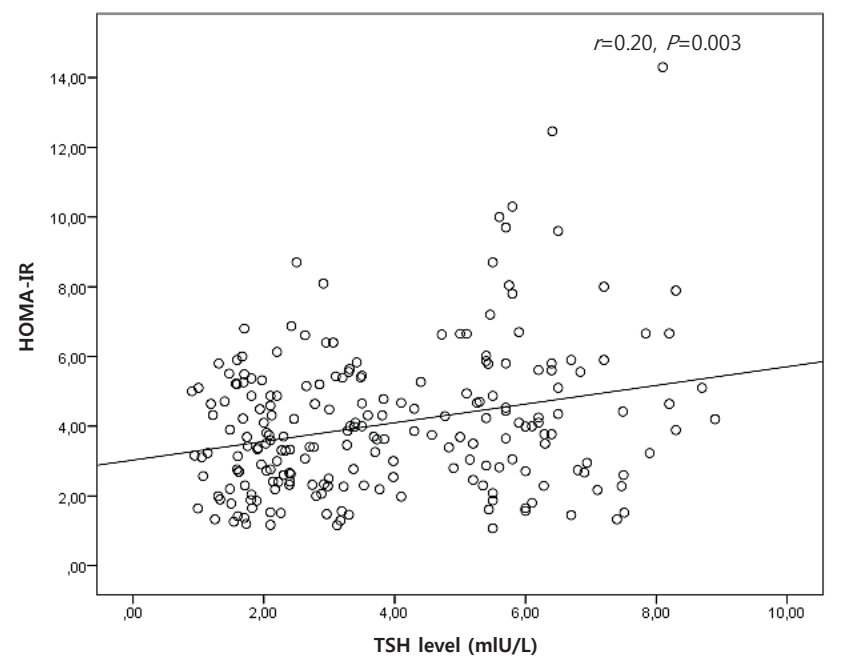

Fig. 2. Correlation between thyrotropin (TSH) level and homeostasis model assessment for insulin resistance (HOMA-IR) in obese patients.

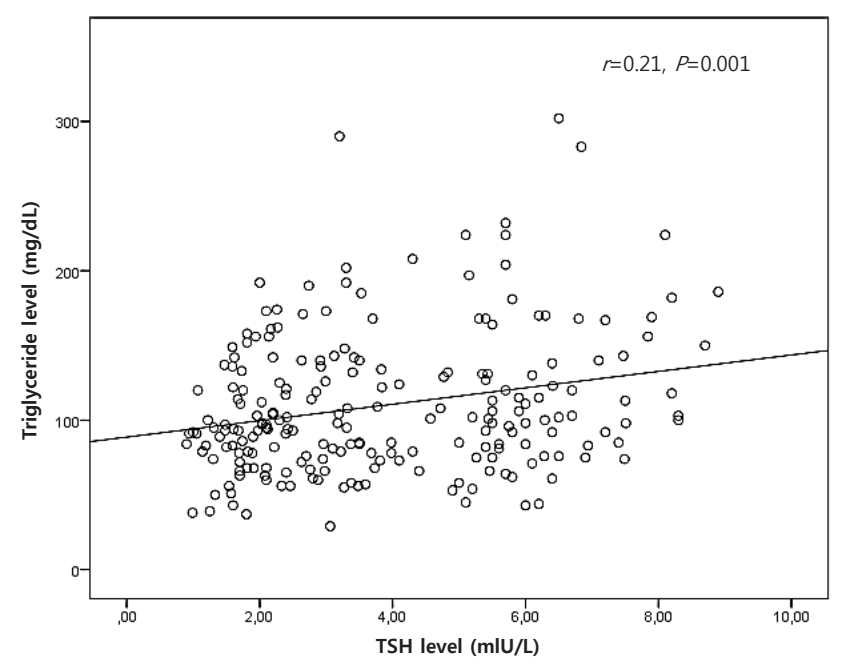

Fig. 3. Correlation between thyrotropin (TSH) level and triglyceride level in obese patients. metabolic parameters in obese children and adolescent with similar BMI was evaluated. Fasting insulin, HOMA-IR, and TG level were found to be higher in elevated TSH group (SH group). Also, HDL-C level was found to be lower in same group. Furthermore, positive correlation between TSH level and insulin, HOMA-IR, TG level were determined.

SH (elevated TSH and normal fT4) was determined in 36\% of 215 obese children and adolescents in this study. Previous studies reported $7 \%-23 \%$ of obese children had moderately elevated TSH levels with normal or slightly elevated fT4. ${ }^{8)}$ Thyroid hormones play a role in thermogenesis and energy consumption. Therefore, the interest in the association between thyroid functions and obesity and gaining weight has increased. ${ }^{13)}$ There are studies reporting a positive correlation between the serum TSH level and BMI beside the studies reporting the opposite. ${ }^{14-18)}$ In a study, the authors found a positive correlation between TSH and BMI, and furthermore, a gradual increase was observed between gaining weight and the TSH level. ${ }^{11)}$ In our study, no correlation was found between the serum TSH level and BMI.

In the present study, no difference was found between the groups with regard to age, sex, and puberty status. In a previous study, no relationship was observed between the TSH level and sex. ${ }^{19)}$ Dahl et al. ${ }^{7)}$ found higher TSH levels in boys than girls in a study conducted with 1796 obese/overweight subjects in childhood and adolescence. In a study conducted with euthyroid obese children, a negative correlation was found between age and puberty status, and TSH levels. ${ }^{10)}$

Thyroid hormones play an important role in glucose and lipid metabolism. Evident hypothyroidism is associated with obesity, insulin resistance, hyperglycemia, dyslipidemia, and increased cardiovascular events. ${ }^{20)}$ However, the influence of $\mathrm{SH}$ on metabolic parameters is still of interest with regard to its clinical relevance as there is no consensus regarding the treatment of $\mathrm{SH}$. Furthermore, the influence of thyroid functions on metabolic parameters has become an issue of interest due to the higher prevalence of $\mathrm{SH}$ in the obese compared to normal weighing subjects. An ample amount of studies are available investigating the association between thyroid hormones and, glucose and lipid metabolism in the obese in childhood and adolescence. ${ }^{9,13,18)}$ While an association was found between TSH and, insulin and HOMA-IR index in some studies, ${ }^{18)}$ other studies did not report such an association. ${ }^{21)}$ In our study, the insulin and HOMA-IR values were found to be higher despite BMI being similar in both groups. In addition, a positive correlation was determined between the TSH level and, insulin and HOMA-IR index.

The levels of TSH and lipid profile were evaluated in previous studies conducted with children and adolescents and a significant correlation was found between the TSH level and TG or TC. $10,22,23)$ On the other hand, there are studies that did not find a correlation between the TSH and lipid concentration. ${ }^{23,24)}$ Different from the others, the HDL-C level was found to be lower in the $\mathrm{SH}$ group compared to the control group in our study. In a population-based study evaluating the serum TSH level and lipid concentration of 30,656 subjects who did not 
have any thyroid diseases, while a linear increase was determined between the TSH level and serum TC, TG, and LDL-C levels, a linear decrease was determined between the TSH level and HDL-C. ${ }^{25)}$ The relationship between TG and HDL-C was reported to be more evident, particularly in overweight subjects. ${ }^{25)}$ Low HDL-C levels accompany high TG levels, particularly in subjects with insulin resistance. The potential mechanism is that HDL particles can be catabolized more easily related to high TG levels. ${ }^{26)}$ Finding high TG levels and low HDL-C levels in the SH group in our study can be explained with this mechanism.

The levels of TSH are seen to decrease when obese individuals lose weight. Therefore, the TSH elevation seems to be a result of obesity rather than the cause. ${ }^{8}$ The TSH level was found to be significantly correlated with TC, LDL-C, insulin, and HOMAIR in a study of Aeberli et al. ${ }^{18)}$ conducted with 206 obese children and adolescents. After these patients lost weight, the TSH levels were observed to decrease and the decrease in TSH was found to predict the decrease in insulin and HOMA-IR. On the other hand, the elevation in TSH in the obese seems to be an adaptation mechanism for increasing the basal metabolic rate. ${ }^{8)}$ In conclusion, negative alterations are common in insulin, HOMA-IR and lipid metabolism in the obese with SH compared to the euthyroid obese, and this condition is correlated with the TSH level. All these results indicate that TSH could be evaluated as a metabolic risk factor in obese children and adolescents.

The study had some limitations. The first limitation was its retrospective design. The second was the absence of a control group including normal weighing children and adolescents.

The present study, which compared the obese children and adolescents with similar BMI, showed that insulin, HOMA-IR, and TG levels were higher and the HDL-C level was lower in patients with SH. In conclusion, it can be said that the TSH may be evaluated as a metabolic risk factor in obese patients.

\section{Conflicts of interest}

No potential conflict of interest relevant to this article was reported.

\section{References}

1. Sabin MA, Kiess W. Childhood obesity: current and novel approaches. Best Pract Res Clin Endocrinol Metab 2015;29:327-38.

2. Nathan BM, Moran A. Metabolic complications of obesity in childhood and adolescence: more than just diabetes. Curr Opin Endocrinol Diabetes Obes 2008;15:21-9.

3. Damiano F, Rochira A, Gnoni A, Siculella L. Action of thyroid hormones, T3 and T2, on hepatic fatty acids: differences in metabolic effects and molecular mechanisms. Int J Mol Sci 2017;18(4). pii: E744. https://doi. org/10.3390/ijms18040744.

4. Santini F, Marzullo P, Rotondi M, Ceccarini G, Pagano L, Ippolito S, et al. Mechanisms in endocrinology: the crosstalk between thyroid gland and adipose tissue: signal integration in health and disease. Eur J Endocrinol 2014;171:R137-52.

5. Monzani A, Prodam F, Rapa A, Moia S, Agarla V, Bellone S, et al. Endocrine disorders in childhood and adolescence. Natural history of subclinical hypothyroidism in children and adolescents and potential effects of replacement therapy: a review. Eur J Endocrinol 2012;168:R1-11.

6. Ghergherehchi R, Hazhir N. Thyroid hormonal status among children with obesity. Ther Adv Endocrinol Metab 2015;6:51-5.

7. Dahl M, Ohrt JD, Fonvig CE, Kloppenborg JT, Pedersen O, Hansen T, et al. Subclinical hypothyroidism in Danish lean and obese children and adolescents. J Clin Res Pediatr Endocrinol 2017;9:8-16.

8. Pacifico L, Anania C, Ferraro F, Andreoli GM, Chiesa C. Thyroid function in childhood obesity and metabolic comorbidity. Clin Chim Acta 2012; 413:396-405.

9. Unüvar T, Anık A, Catlı G, Esen I, Abacı A, Büyükgebiz A, et al. Isolated hyperthyrotropinemia in childhood obesity and its relation with metabolic parameters. J Endocrinol Invest 2014;37:799-804.

10. Aypak C, Türedi O, Yüce A, Görpelioğlu S. Thyroid-stimulating hormone (TSH) level in nutritionally obese children and metabolic co-morbidity. J Pediatr Endocrinol Metab 2013;26:703-8.

11. Knudsen N, Laurberg P, Rasmussen LB, Bülow I, Perrild H, Ovesen L, et al. Small differences in thyroid function may be important for body mass index and the occurrence of obesity in the population. J Clin Endocrinol Metab 2005;90:4019-24.

12. Reinehr T. Obesity and thyroid function. Mol Cell Endocrinol 2010; 316:165-71.

13. Rumińska M, Witkowska-Sędek E, Majcher A, Pyrżak B. Thyroid function in obese children and adolescents and its association with anthropometric and metabolic parameters. In: Pokorski M, editor. Prospect in pediatric diseases medicine. advances in experimental medicine and biology. Cham: Springer, 2016:33-41.

14. Emokpae MA, Adeleke SI, Uwumarongie HO. Subclinical hypothyroidism in childhood obesity and its correlation with lipoproteins. Afr J Med Med Sci 2011;40:361-5.

15. Stichel H, l'Allemand D, Grüters A. Thyroid function and obesity in children and adolescents. Horm Res 2000;54:14-9.

16. Marras V, Casini MR, Pilia S, Carta D, Civolani P, Porcu M, et al. Thyroid function in obese children and adolescents. Horm Res Paediatr 2010; 73:193-7.

17. Michalaki MA, Vagenakis AG, Leonardou AS, Argentou MN, Habeos IG, Makri MG, et al. Thyroid function in humans with morbid obesity. Thyroid 2006;16:73-8.

18. Aeberli I, Jung A, Murer SB, Wildhaber J, Wildhaber-Brooks J, Knöpfli $\mathrm{BH}$, et al. During rapid weight loss in obese children, reductions in TSH predict improvements in insulin sensitivity independent of changes in body weight or fat. J Clin Endocrinol Metab 2010;95:5412-8.

19. Elmlinger MW, Kühnel W, Lambrecht HG, Ranke MB. Reference in tervals from birth to adulthood for serum thyroxine (T4), triiodothyronine (T3), free T3, free T4, thyroxine binding globulin (TBG) and thyrotropin (TSH). Clin Chem Lab Med 2001;39:973-9.

20. Klein I, Ojamaa K. Thyroid hormone and the cardiovascular system. N Engl J Med 2001;344:501-9.

21. Reinehr T, Isa A, de Sousa G, Dieffenbach R, Andler W. Thyroid hormones and their relation to weight status. Horm Res 2008;70:51-7.

22. Shalitin S, Yackobovitch-Gavan M, Phillip M. Prevalence of thyroid dysfunction in obese children and adolescents before and after weight reduction and its relation to other metabolic parameters. Horm Res 2009; 71:155-61.

23. Reinehr T, de Sousa G, Andler W. Hyperthyrotropinemia in obese children is reversible after weight loss and is not related to lipids. J Clin Endocrinol Metab 2006;91:3088-91.

24. Grandone A, Santoro N, Coppola F, Calabrò P, Perrone L, Del Giudice EM. Thyroid function derangement and childhood obesity: an Italian experience. BMC Endocr Disord 2010;10:8.

25. Asvold BO, Vatten LJ, Nilsen TI, Bjøro T. The association between TSH within the reference range and serum lipid concentrations in a populationbased study. The HUNT Study. Eur J Endocrinol 2007;156:181-6.

26. Rashid S, Watanabe T, Sakaue T, Lewis GF. Mechanisms of HDL lowering in insulin resistant, hypertriglyceridemic states: the combined effect of HDL triglyceride enrichment and elevated hepatic lipase activity. Clin Biochem 2003;36:421-9. 